\title{
Effect of Nano Clay inclusions on Mechanical Properties of Thermoplastics
}

\author{
G. Surya Rao ${ }^{1}$ Prof. H. Ravi Shankar ${ }^{2}$ \\ ${ }^{1}$ Department of Mechanical Engineering.Gitam University, Visakhapatnam 530045, Andhra \\ Pradesh, India \\ ${ }^{2}$ Department of Mechanical Engineering.Gitam University, Visakhapatnam 530045, Andhra \\ Pradesh, India
}

\begin{abstract}
ARTICLE INFO
Keywords:

Mechanical properties, Nano clay, Twin screw extruder and Injection moulding process.
\end{abstract}

\begin{abstract}
Polymer has been widely used now-a-days in many fields. Their properties make them useful in much engineering applications. Owing to their poor mechanical properties in engineering applications are seldom found. Hence, in the present study it is aimed to enhance the mechanical properties of thermoplastics to enable their usage in engineering applications such as automotive bumpers, gears etc. Recently many researchers tried to improve mechanical properties of polymers using Nano clay inclusions. In the present study polypropylene (PP), Acrylonitrile butadiene styrene (ABS) and high density polyethylene (HDPE) thermoplastics polymers are considered. Nano clay included polymer composites are fabricated with an intention to enhance their mechanical properties. Often these materials are subjected to various testing procedures and mechanical properties of these composites are to be studied. Hence, in the present work PP, ABS and HDPE Nano clay composites are fabricated using twin screw extruder for blending Nano clay in different percentage to study the effect of Nano clay weight fraction on these properties. Samples fabricated using injection molding process. The samples are fabricated at different weight percentages of nanoclay and Often these materials are exposed to certain testing like tensile and fatigue. More after the mechanical properties of PP, ABS and HDPE with Nanoclay polymer composites were observing and how much percentage of strength increasing when comparing with the pure samples. Among the selected thermoplastics ABS Nano composites exhibits higher mechanical properties and by increasing the nanoclay weight percentage in each and every component the mechanical properties also increasing gradually and all are exhibits their better results at $5 \%$ of nanoclay with PP, ABS and HDPE.
\end{abstract}




\section{Introduction}

Polymer nanocomposites are polymers that have been reinforced with small quantities of nanosized particles (nanofillers). These materials represent a radical alternative to conventional filled polymers or polymer blends. In contrast to conventional composites, where the reinforcement is on the order of micrometres, polymer nanocomposites are exemplified by discrete constituents on the order of a few nanometres. An important class of nanofillers involves nanoclays belonging to the kaolin group, such as montmorillonite. Kaolin $\left(\mathrm{Al}_{2} \mathrm{Si}_{2} \mathrm{O}_{5}(\mathrm{OH})_{4}\right)$ is a 1:1 phyllosilicate containing a gibbsite octahedral layer and a silicon oxide tetrahedral sheet and there is a certain degree of Van der Waals attraction and hydrogen bonding between the hydroxyl groups of the gibbsite layer and the oxygen atoms of the adjoining silica layer, providing a large cohesive energy. To produce nanocomposite materials with optimum properties and performance, these nanoclays must be intercalated with the polymer matrix and also completely Exfoliated. However, because these nanoclays are hydrophilic by nature, it is not always easy to accomplish their exfoliation in a hydrophobic polymer matrix like polypropylene (PP), high density polyethylene (HDPE) and acrylonitrile butadiene styrene (ABS). The process, however, can be facilitated if the clay is treated with an organic intercalant, which replaces the metal cations located between the layers and increases the interlayer spacing. This aids further separation and eventual exfoliation when the treated clay is mixed with molten polymer in a melt processing procedure.

It is known that nanocomposite materials can be processed by traditional melt-processing methods. The processing of these materials is important in determining their final morphological properties. Mixing facilitates nanoscale dispersion and can lead to clay and/or polymer alignment. The degree of shear during moulding determines not only the degree of clay alignment, but also the degree of polymer orientation. In the case of injection moulding, the clay platelets can also enhance the alignment of the polymer chains. The addition of nanoparticles in crystalline polymers was found, in general, not to affect considerably the crystallinity of the resulting nanocomposite materials, even though there may be some changes in particular nanocomposite systems. It has been proposed, however, that these particles produce a much larger number of nucleating sites and in turn greatly reduce the size. The physical and morphological characteristics can have a great influence on the mechanical properties of nanocomposite products. However, their exact effects on the water absorption behaviour of this class of materials have not been widely discussed in the literature. In the present study, extensive work is undertaken to further understand the mechanism of moisture transport in both neat polypropylene (PP), high density polyethylene (HDPE) and Acrylonitrile Butadiene Styrene (ABS) and its nanocomposites containing different amounts of nanoclay, as well as to characterize its effect on the tensile and flexural properties of materials.

\section{Experimental Procedure}

\subsection{Raw materials}

Polypropylene (PP), High Density Polyethylene (HDPE) and Acrylonitrile Butadiene Styrene (ABS). Kaolin Clay is a naturally occurring material composed of fine-grained size was used as a nanoparticle. All materials were dried at $55{ }^{\circ} \mathrm{C}$ for 10 hours in vacuum.

2.2 Nanocomposites preparation

PP, ABS, HDPE and Nano clay blends were prepared via melt intercalation method by twin screw extruder. The process undergo at

different temperature ranges from $180{ }^{\circ} \mathrm{C}$ to $215{ }^{\circ} \mathrm{C} 170{ }^{\circ} \mathrm{C}$ to $212{ }^{\circ} \mathrm{C}$ and $135{ }^{\circ} \mathrm{C}$ to $170{ }^{\circ} \mathrm{C}$. Nano clay is used as a filler with PP, ABS and HDPE at different weight ratios $1 \mathrm{Wt} \%, 3 \mathrm{Wt} \%, 5 \mathrm{Wt} \%$ in extrusion process. The material enters through the feed throat from hopper. The twin screws in extrusion machine 
forces the material and the material will be out from the die in the form of wires. The composite material wires obtained from extrusion process will be cooled in water bath.

Pallets from extrusion and cutting process will be dried in oven at $55{ }^{\circ} \mathrm{C}$ for removal of moisture content. Granulated or pallets is fed from a hopper into the Injection Moulding machine. The Injection Moulding machine consists of a hollow steel barrel, containing a rotating screw. The screw carries the plastic along the barrel to the mould. The screw is forced back as the melted plastic collects at the end of the barrel. Once enough plastic has collected a hydraulic ram pushes the screw forward injecting the plastic through a sprue into a mould cavity. The mould is warmed before injecting and the plastic is

injected quickly to prevent it from hardening before the mould is full. Pressure is maintained for a short time (dwell time) to prevent the material creeping back during setting (hardening). This prevents shrinkage and hollows, therefore giving a better quality product. The moulding is left to cool before removing (ejected) from the mould. Finally, the specimen will be out from the injection moulding machine

\subsection{Preparation of tests specimens}

Pallets from extrusion and cutting process will be dried in oven at $55^{\circ} \mathrm{C}$ for removal of moisture content. The specimens from the injection moulding machine undergo following stages

Stage 1:Granulated or pallets is fed from a hopper into the Injection Moulding machine.

Stage 2: The Injection Moulding machine consists of a hollow steel barrel, containing a rotating screw. The screw carries the plastic along the barrel to the mould.

Stage 3: The screw is forced back as the melted plastic collects at the end of the barrel.Once enough plastic has collected a hydraulic ram pushes the screw forward injecting the plastic through a sprue into a mould cavity. The mould is warmed before injecting and the plastic is injected quickly to prevent it from hardening before the mould is full.

Stage 4: Pressure is maintained for a short time (dwell time) to prevent the material creeping back during setting (hardening). This prevents shrinkage and hollows, therefore giving a better quality product.The moulding is left to cool before removing (ejected) from the mould. The moulding takes on the shape of the mould cavity.

2.4 Tensile and Flexure test of PP, ABS and HDPE composites

The specimens of PP,ABS and HDPE will be removed from constant water bath and dried up, and cooled to room temperature in order to determine the mechanical properties such as tensile strength and Young's modulus from machine called INSTRON servo hydraulic machine with a cross-head speed of $3.0 \mathrm{~mm} / \mathrm{min}$.
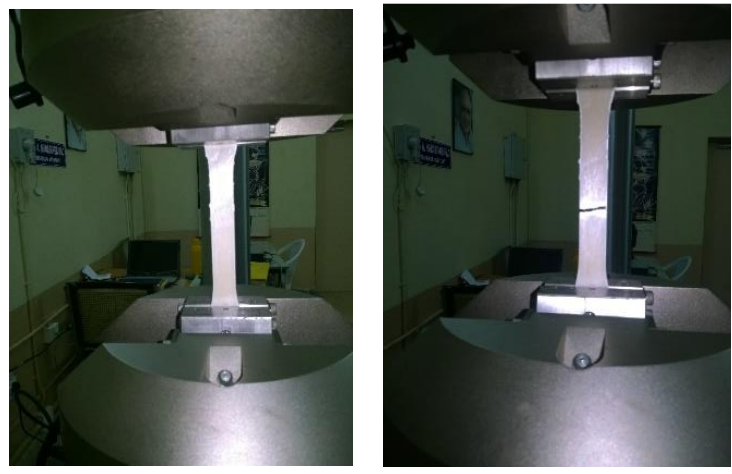

Fig.2 Tensile Test of composite Material 

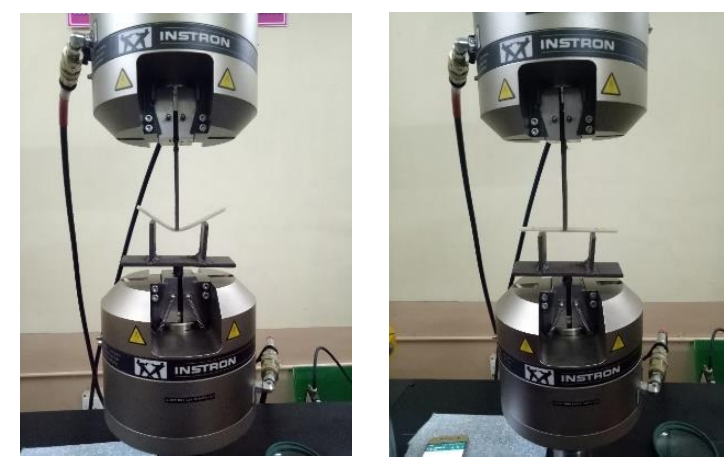

Fig.3 Flexural test of composite material
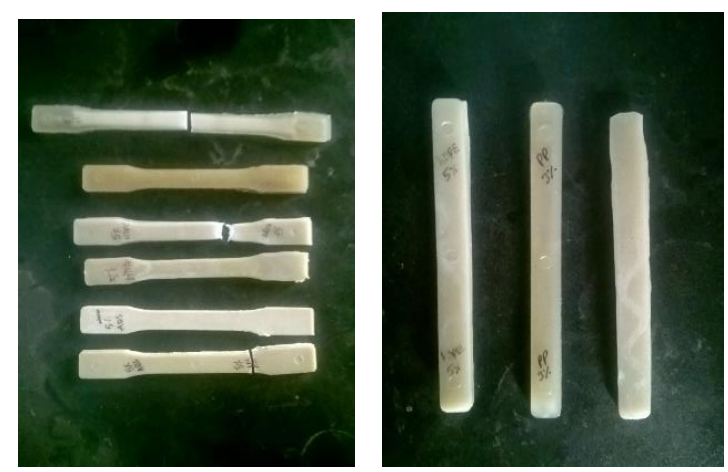

Fig 4 Images of the specimens before and after loading (PP, ABS and HDPE).

\section{Results and Discussion}

\subsection{TENSILE TEST ON ABS:}

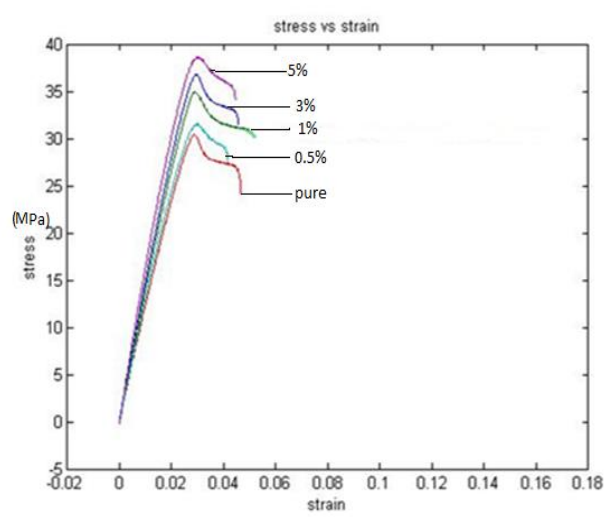

Fig STRESS VS STRAIN DIAGRAM

From The above graph of the tensile test performed on ABS between stress on y-axis andstrain on $\mathrm{x}$-axis, the tensile test of ABS with nanoclay addition of weight percentage at 5\% got more tensile properties when compared to the other percentages of nanoclay additions with ABS material.

\section{GRAPH BETWEEN \%NANO CLAY VS UTS TO ABS}




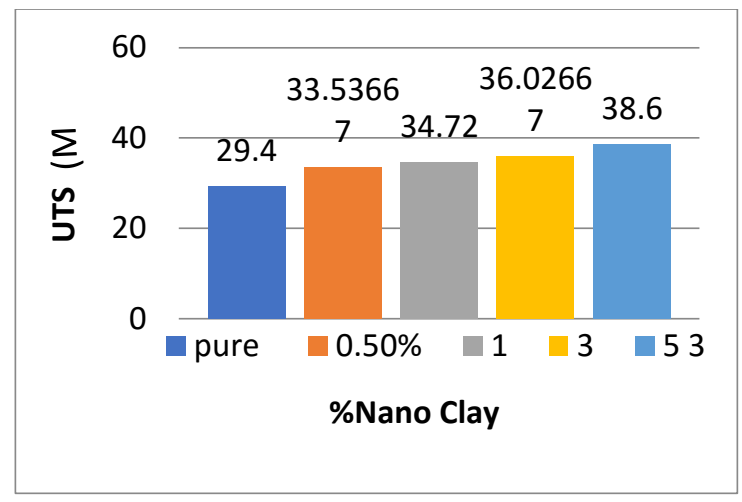

From the fig graph between $\%$ of nano clay on $\mathrm{x}$-axis and uts on y-axis.while observing the graph with addition of nano clay at different percentage increases the ultimate tensile strength also increases. As a clay content increases from $1 \mathrm{Wt} \%$ to $5 \mathrm{Wt} \%$ ultimate tensile stress tends to increase when compared to other percentages of Nano clay and other materials like PP and HDPE.

\section{PERCENTAGE OF INCRIMENT IN TENSILE STRENGTH TO ABS:}

\begin{tabular}{|c|c|c|c|c|}
\hline Tensile strength & $0.5 \%$ & $1 \%$ & $3 \%$ & $5 \%$ \\
\hline ABS & 14.07 & 18.09 & 22.58 & 30.95 \\
\hline
\end{tabular}

After the tensile test on ABS with addition of nanoclay percentages by the observation of the table at 5\% it shows more percentage of increment in tensile strength when compared to the other percentages of nanoclay inclusions. At $5 \%$ of nanoclay with ABS shows $30.95 \%$ of increment when compared to the pure values.

\section{GRAPH BETWEEN \%NANO VS E TO ABS}

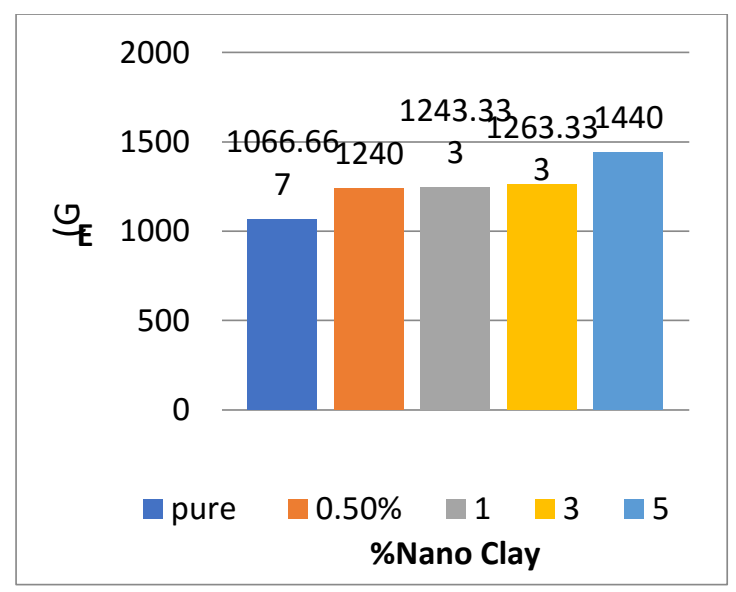

Fig graph between \% of nano clay and $\mathrm{E}$

The above graph between \%of nano clay on $\mathrm{x}$-axis and modulus on y-axis. By the observation of above graph while increasing the \%of nano clay the modulus also increases. By the observations of all the percentages with increasing the nanoclay percentage the tensile properties of material increases at every stages .As a clay content increases from $1 \mathrm{Wt} \%$ to $5 \mathrm{Wt} \%$ modulus tends to increase when compared to other percentages of Nano clay and other materials like PP and HDPE. 
PERCENTAGE OF INCRIMENT IN E TO ABS:

\begin{tabular}{|c|c|c|c|c|}
\hline E & $\mathbf{0 . 5 \%}$ & $\mathbf{1 \%}$ & $\mathbf{3 \%}$ & $\mathbf{5 \%}$ \\
\hline ABS & $\mathbf{1 6 . 2 4}$ & 16.56 & $\mathbf{1 8 . 4 3}$ & $\mathbf{3 5}$ \\
\hline
\end{tabular}

To the ABS material at 5\% of nanoclay percentages shows more growth in $\mathrm{E}$ when compares to the other percentages. At this stage it exhibits $35 \%$ of growth when compares to the other percentages.

\section{GRAPH BETWEEN \%NANO VS TENSILE STRESS AT YIELD TO ABS:}

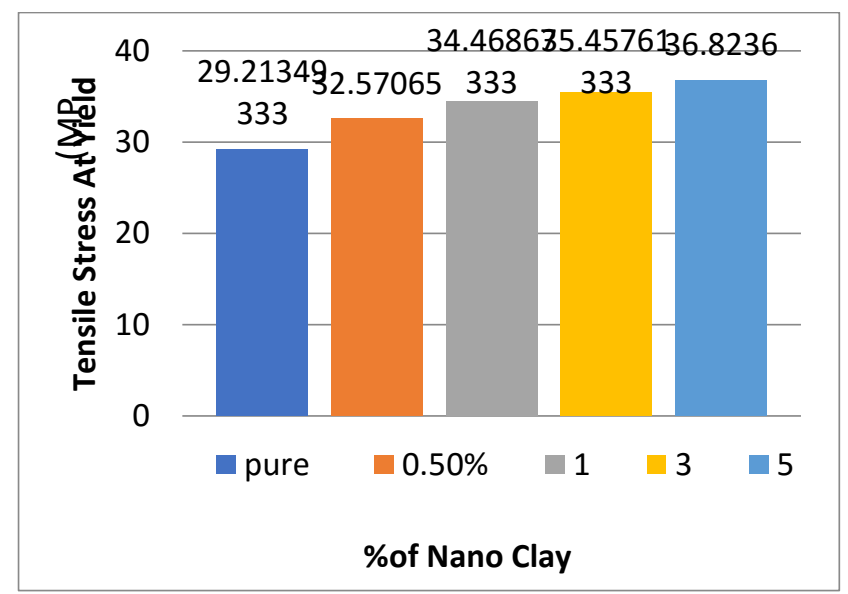

Fig graph between \%ofnano clay vs stress at yield

From the fig5.1(d) between $\%$ of nano clay on x-axis and stress at yield on y-axis observes that the maximus value obtained at the percentage of $\% 5$.That means while increasing the nano clay percentage the stress yield also increasesgradually .As a clay content increases from $1 \mathrm{Wt} \%$ to $5 \mathrm{Wt} \%$ tensile stress tends to increase when compared to other percentages of Nano clay and other materials like HDPE and ABS.

\subsection{TENSILE TEST ON HDPE}

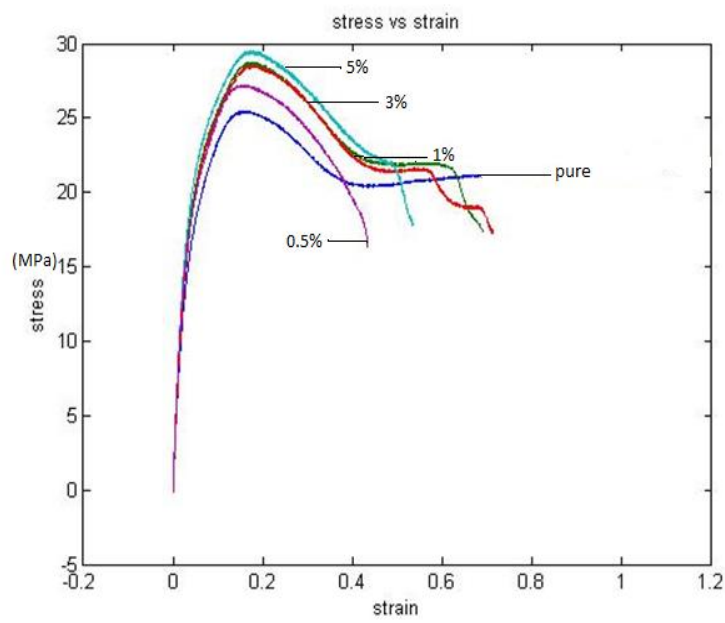

Fig GRAPH BETWEEN STRESS AND STRAIN 
The above graph between stress and starin on $\mathrm{x}, \mathrm{y}$-axies for the material of hdpe. While observing the graph that the nano clay weight percentage of $\% 5$ obtains the maximum value that means while increasing the nanocaly weight percentage the tensile properties of material increasing gradually. And compared this graph with $\mathrm{ABS}$, the tensile strength of that material is little bit more when we make comparison between HDPE and ABS.

\section{GRAPH BETWEEN NANOCLAY \% VS E TO HDPE:}

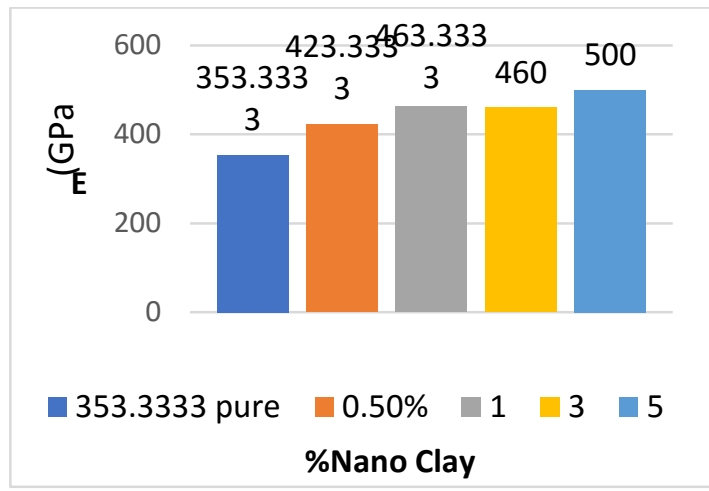

Fig graph between \%nano clay and $\mathrm{E}$

The above graph between \% of nano clay on $\mathrm{x}$-axis and modulus on $\mathrm{y}$-axis. By the observation of above graph while increasing the \%of nano clay the modulus also increases. By the observations of all the percentages with increasing the nanoclay percentage the tensile properties of material increases at every stages .As a clay content increases from $1 \mathrm{Wt} \%$ to $5 \mathrm{Wt} \%$ modulus tends to increase when compared to other percentages of Nano clay and other materials like PP and ABS.

\section{PERCENTAGE OF INCRIMENT IN E TO HDPE:}

\begin{tabular}{|c|c|c|c|c|}
\hline E & $\mathbf{0 . 5 \%}$ & $\mathbf{1 \%}$ & $\mathbf{3 \%}$ & $\mathbf{5 \%}$ \\
\hline HDPE & $\mathbf{1 9 . 8 1}$ & $\mathbf{3 1 . 1 3}$ & $\mathbf{3 0 . 1 3}$ & $\mathbf{3 2 . 4}$ \\
\hline
\end{tabular}

To the HDPE material at 5\% of nanoclay percentages shows more growth in $\mathrm{E}$ when compares to the other percentages. At this stage it exhibits $32.4 \%$ of growth when compares to the other percentages.

\section{GRAPH BETWEEN NANOCLAY \% VS UTS:}

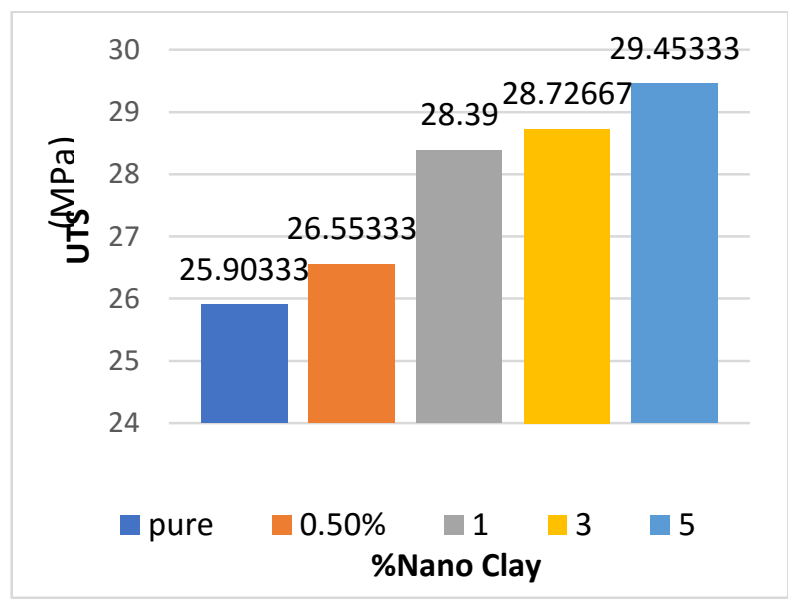

Fig Graph between \% nano clay and uts 
From the observation of above graph between \%of nanoclay and uts on $\mathrm{x}, \mathrm{y}$-axis, The ultimate tensile strength of material increases while increasing the addition of nanoclay weight percentage to the material.As a clay content increases from $1 \mathrm{Wt} \%$ to $5 \mathrm{Wt} \%$ ultimate tensile stress tends to increase when comparing to other percentages of Nano clay and other materials like PP and ABS.

\section{PERCENTAGE OF INCRIMENT IN TENSILE STRENGTH TO HDPE:}

\begin{tabular}{|c|l|c|c|c|}
\hline Tensile strength & $0.5 \%$ & $1 \%$ & $3 \%$ & $5 \%$ \\
\hline HDPE & 2.5 & 9.599 & 10.89 & 13.7 \\
\hline
\end{tabular}

After the tensile test on HDPE with addition of nanoclay percentages by the observation of the table at 5\% it shows more percentage of increment in tensile strength when compared to the other percentages of nanoclay inclusions. At 5\% of nanoclay with HDPE shows $13.7 \%$ of increment when compared to the pure values.

\section{GRAPH BETWEEN \%NANO VS TENSILE STRESS AT YIELD TO HDPE:}

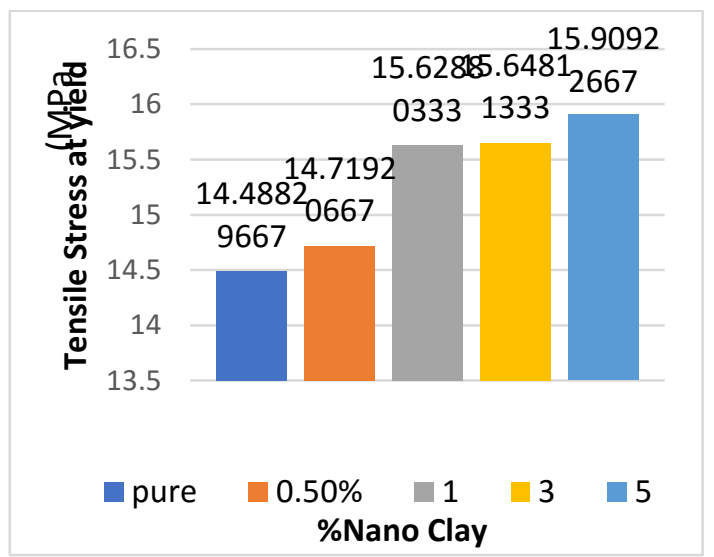

Fig graph between \% nano clay and stress at yield

By the observation of above graph between \%of nano clay and stress at yield on $\mathrm{x}, \mathrm{y}$-axis that the stress at yield increases gradually while increasing the nano clay percentage of weight addition to the component.As a clay content increases from $1 \mathrm{Wt} \%$ to $5 \mathrm{Wt} \%$ tensile stress tends to increases when compares to other percentages of Nano clay and other materials like HDPE and ABS.

\subsection{TENSILE TEST ON POLYPROPENE:} STRESS VS STRAIN TO POLYPROPENE: 


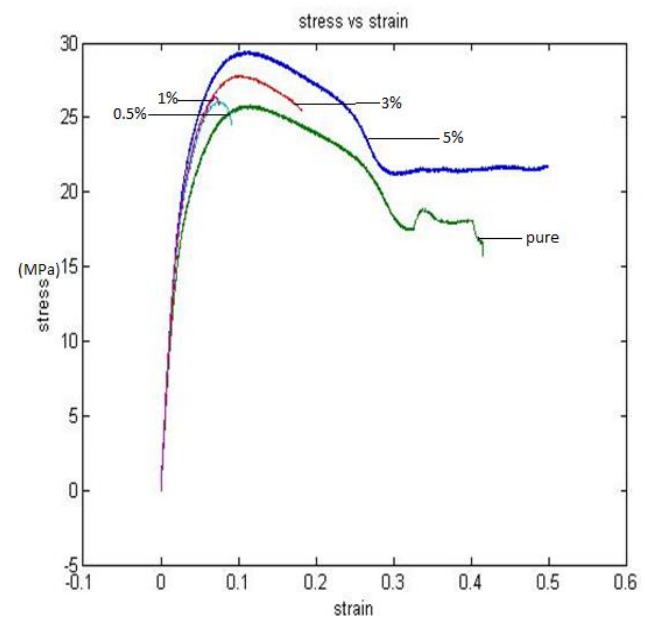

Fig stress vs strain graph to polypropene

From the above fig between stress and strain on $x, y$-axis observes that the nano clay weight percentage of $5 \%$ obtains the maximum values. As the nano clay weight percentage increases tensile properties of the material also increases gradually.

\section{GRAPH BETWEEN UTS VS \%NANO TO PP:}

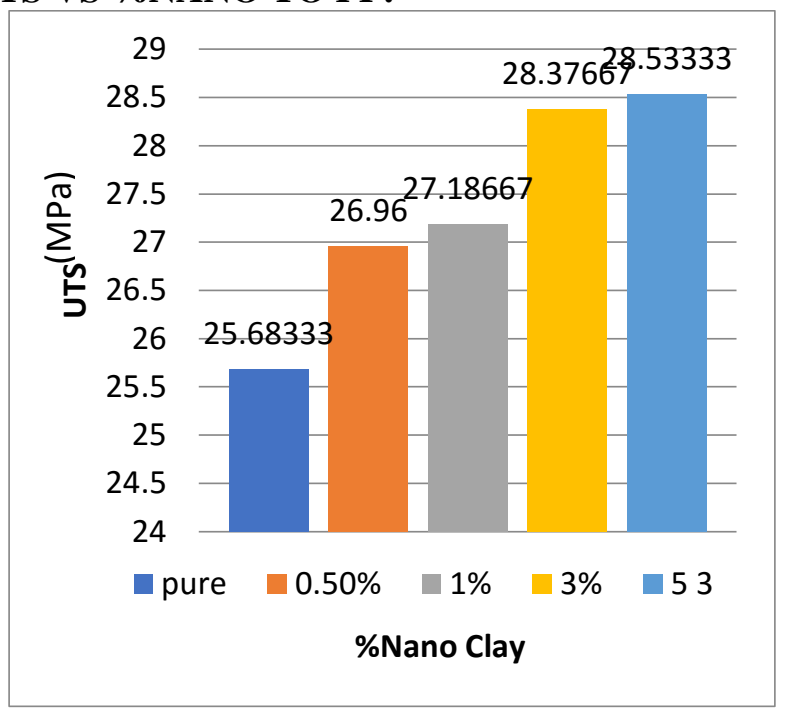

Fig graph between uts vs \% nano clay

From the above graph between ultimate tensile strength and \%of nano clay on $\mathrm{x}, \mathrm{y}$ axis observing that graph the ultimate tensile strength increases while increasing the percentage of nanoclay to the component. As a clay content increases from $1 \mathrm{Wt} \%$ to $5 \mathrm{Wt} \%$ ultimate tensile strength tends to increase when compared to other percentages of Nano clay and other materials like HDPE and ABS.

\section{PERCENTAGE OF INCRIMENT IN TENSILE STRENGTH TO PP:}

\begin{tabular}{|c|c|c|c|c|}
\hline Tensile strength & $0.5 \%$ & $1 \%$ & $3 \%$ & $5 \%$ \\
\hline PP & 4.97 & 5.85 & 10.48 & 11.09 \\
\hline
\end{tabular}

After the tensile test on PP with addition of nanoclay percentages by the observation of the table at 5\% it shows more percentage of increment in tensile strength when compared to the other percentages of 
nanoclay inclusions. At 5\% of nanoclay with PP shows $11.09 \%$ of increment when compared to the pure values.

\section{Graph between \%NANO VS E to pp:}

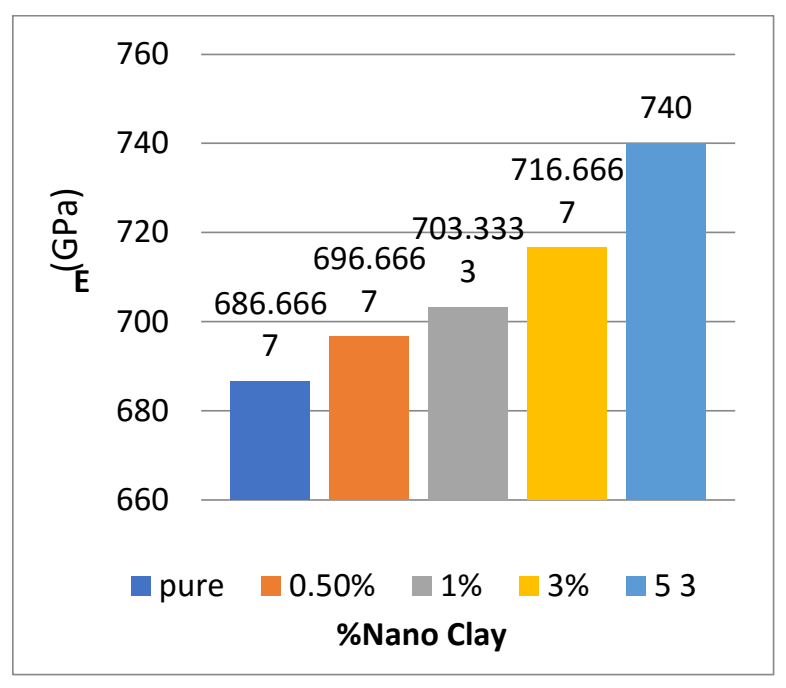

\section{Graph between \%NANO VS E}

From the above between \%nano clay and $\mathrm{E}$ on $\mathrm{x}, \mathrm{y}$-axis respectively. From that as the nano clay percentage increases the modulus also increases respectively. As a clay content increases from $1 \mathrm{Wt} \%$ to $5 \mathrm{Wt} \%$ modulus tends to increase when compares to other percentages of Nano clay and other materials like HDPE and ABS.

\section{PERCENTAGE OF INCRIMENT IN E TO PP:}

\begin{tabular}{|c|c|c|c|c|}
\hline $\mathbf{E}$ & $\mathbf{0 . 5 \%}$ & $1 \%$ & $3 \%$ & $5 \%$ \\
\hline PP & 1.45 & 2.42 & 4.36 & 7.76 \\
\hline
\end{tabular}

To the PP material at 5\% of nanoclay percentages shows more growth in E when compares to the other percentages. At this stage it exhibits $7.76 \%$ of growth when compares to the other percentages

\section{GRAPH BETWEEN \%NANO VS TENSILE STRESS AT YIELD TO PP:}




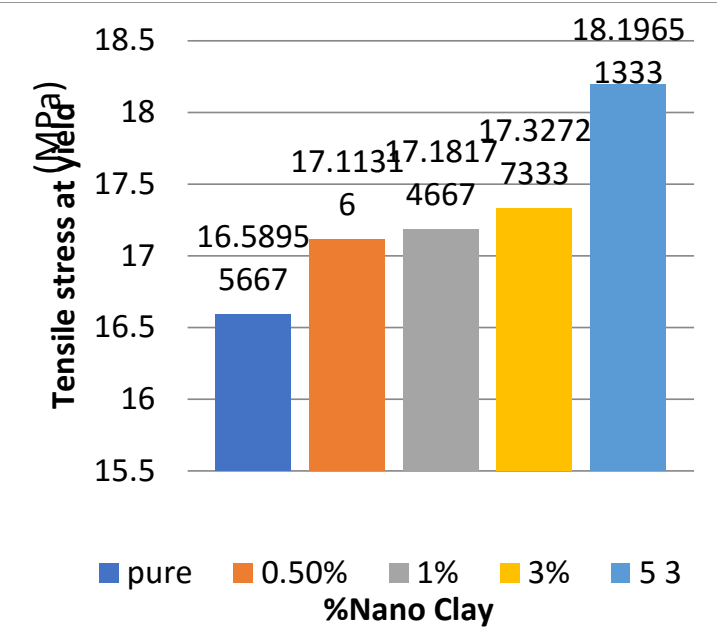

Fig graph between \% nano clay and stress at yield

The above graph which is drawn between \%of nano clay and stress at yield on $\mathrm{x}, \mathrm{y}$-axis respectively.from that graph the stress at yield increases gradually while increasing the nano clay percentage of weight addition to the component.As a clay content increases from $1 \mathrm{Wt} \%$ to $5 \mathrm{Wt} \%$ tensile stress tends to increase when compared to other percentages of Nano clay and other materials like HDPE and ABS.

\subsection{FLEXTURE TEST ON HDPE:}

\section{GRAPH BETWEEN \%NANO CLAY AND E:}

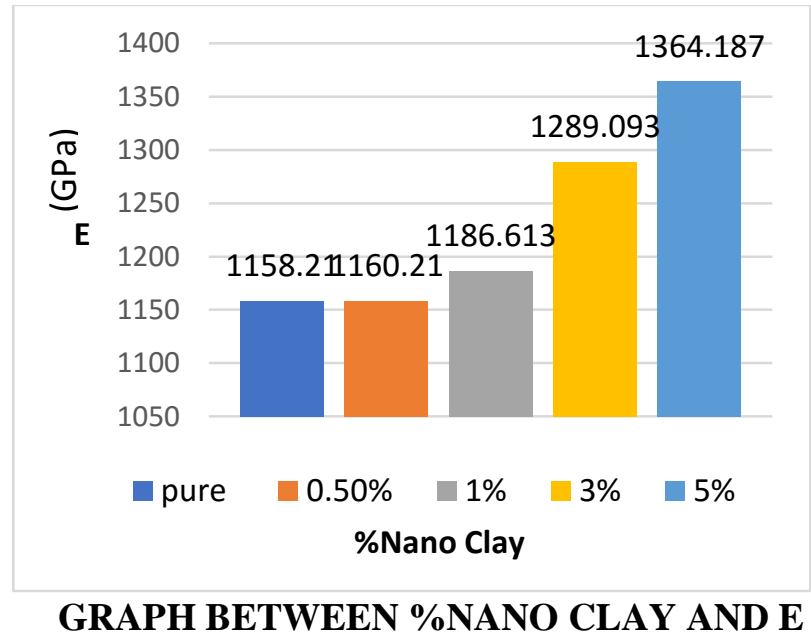

From the above graph between \%nano clay and $\mathrm{E}$ on $\mathrm{x}, \mathrm{y}$-axis observes that as the nano clay percentage increases the modulus also increases gradually .As a clay content increases from $1 \mathrm{Wt} \%$ to $5 \mathrm{Wt} \%$ modulus tends to increase when compares to other percentages of Nano clay and other materials like $\mathrm{PP}$ and $\mathrm{ABS}$. 
PERCENTAGE OF INCRIMENT IN E TO HDPE:

\begin{tabular}{|l|c|c|l|l|}
\hline E & $\mathbf{0 . 5 \%}$ & $1 \%$ & $3 \%$ & $5 \%$ \\
\hline HDPE & 1.2 & 2.45 & 11.3 & 17.78 \\
\hline
\end{tabular}

To the HDPE material at 5\% of nanoclay percentages shows more growth in $\mathrm{E}$ when compares to the other percentages. At this stage it exhibits $17.78 \%$ of growth when compares to the other percentages.

\section{Graph between \%NANO VS Maximum Stress to HDPE:}

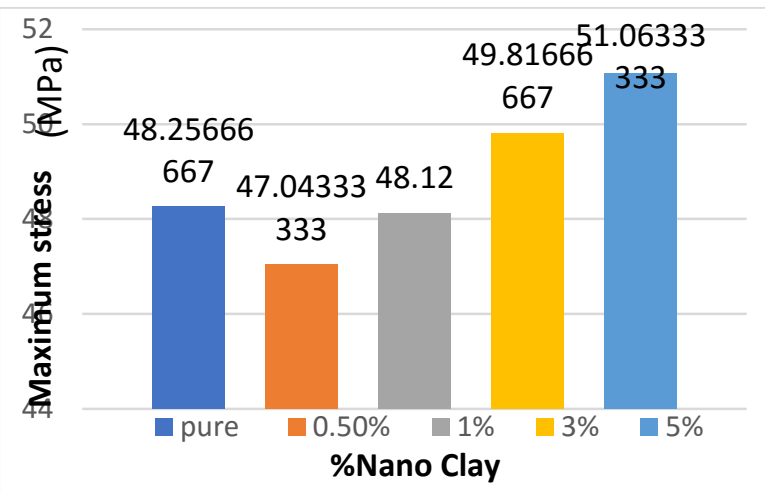

From the fig graph between \%of nano clay and maximum stress on $\mathrm{x}, \mathrm{y}$-axis, While observing the whole result of it as the increase of nanoclay addition of weight percentage increases maximum stress also increases gradually. As a clay content increases from $1 \mathrm{Wt} \%$ to $5 \mathrm{Wt} \%$ maximum stress tends to increase when compares to other percentages of Nano clay and other materials like PP and ABS.

\section{Graph between \%NANO VS Flexure load at Maximum Flexure stress to HDPE:}

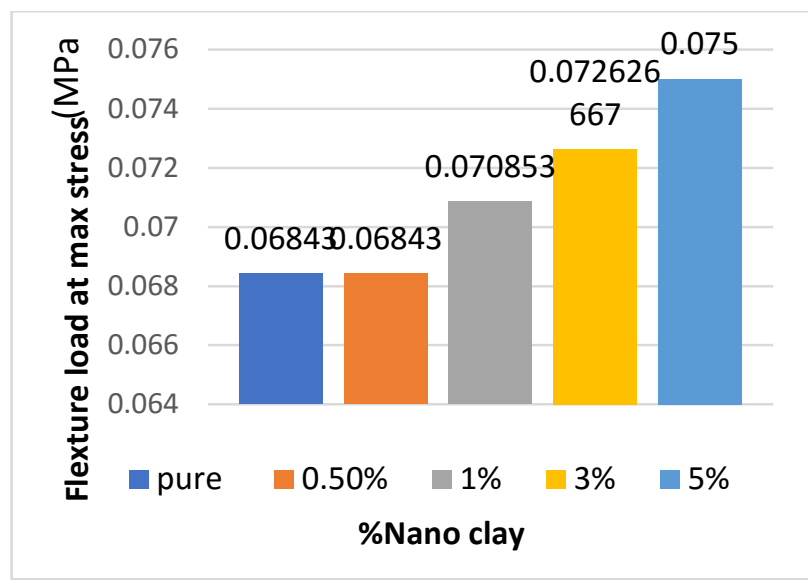

\section{Graph between \%NANO VS Flexure load at Maximum Flexure stress}

By the observation of above graph between \%of nano clay and flexure load at maximum flexure stress on $\mathrm{x}, \mathrm{y}$-axis, that the whole result of it is by increases of nanoclay addition of weight percentage increases flexureload also increases gradually. As a clay content increases from $1 \mathrm{Wt} \%$ to $5 \mathrm{Wt} \%$ flexural stress tends to increases when compared to other percentages of Nano clay and other materials like $\mathrm{PP}$ and ABS.

\section{FLEXTURE TEST ON POLYPROPENE:}


GRAPH BETWEEN \%NANO CLAY AND E:

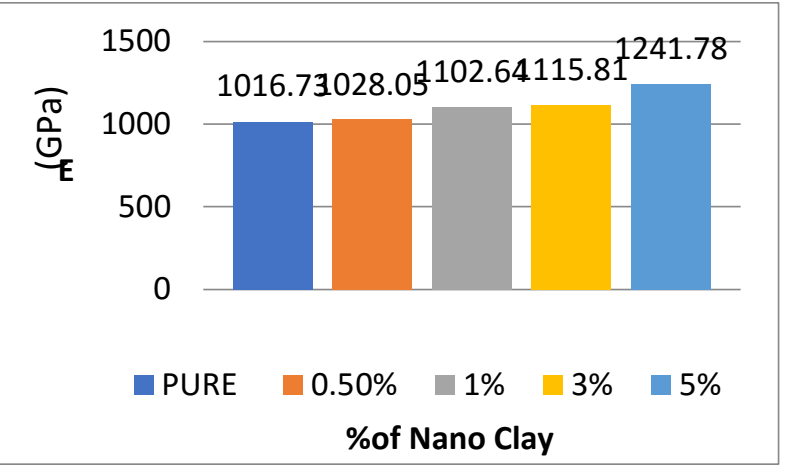

From the above between \%nano clay and $\mathrm{E}$ on $\mathrm{x}, \mathrm{y}$-axis, observes that as the nano clay perentage increases the modulus also increases gradually. As a clay content increases from $1 \mathrm{Wt} \%$ to $5 \mathrm{Wt} \%$ young's modulus increases when compares to other percentages of Nano clay and other materials like HDPE and ABS.

\section{PERCENTAGE OF INCRIMENT IN E TO PP:}

\begin{tabular}{|c|l|l|l|c|}
\hline E & $\mathbf{0 . 5 \%}$ & $1 \%$ & $\mathbf{3 \%}$ & $\mathbf{5 \%}$ \\
\hline PP & 1.18 & $\mathbf{8 . 4}$ & $\mathbf{9 . 8 5}$ & $\mathbf{2 2 . 1}$ \\
\hline
\end{tabular}

To the PP material at 5\% of nanoclay percentages shows more growth in $\mathrm{E}$ when compares to the other percentages. At this stage it exhibits $22.1 \%$ of growth when compares to the other percentages.

\section{Graph between \%NANO VS Maximum Stress to pp:}

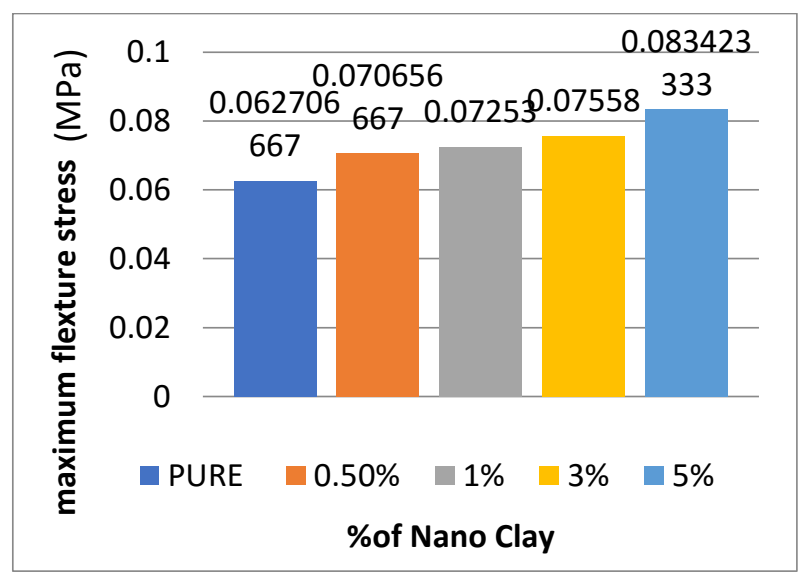

\section{Fig between \%NANO VS Maximum Stress}

The above graph between \%of nano clay and maximum stress on $\mathrm{x}, \mathrm{y}$-axis, While observing the whole result of it as the increase of nanoclay addition of weight percentage increases maximum stress also increases.As a clay content increases from $1 \mathrm{Wt} \%$ to $5 \mathrm{Wt} \%$ maximum stress will increase when compares to other percentages of Nano clay and other materials like HDPE and ABS.

\section{PERCENTAGE OF INCRIMENT IN FLEXTURE STRENGTH TO PP:}




\begin{tabular}{|c|c|c|c|c|}
\hline FLEXTURE LOAD & $0.5 \%$ & $1 \%$ & $3 \%$ & $5 \%$ \\
\hline PP & 1.2 & 1.62 & 2.06 & 3.45 \\
\hline
\end{tabular}

After the flexture test on PP with addition of nanoclay percentages by the observation of the table at 5\% it shows more percentage of increment in flexture strength when compared to the other percentages of nanoclay inclusions. At 5\% of nanoclay with PP shows $3.45 \%$ of increment when compared to the pure values.

\section{Graph between \%NANO VS Flexure load at Maximum Flexure stress to pp:}

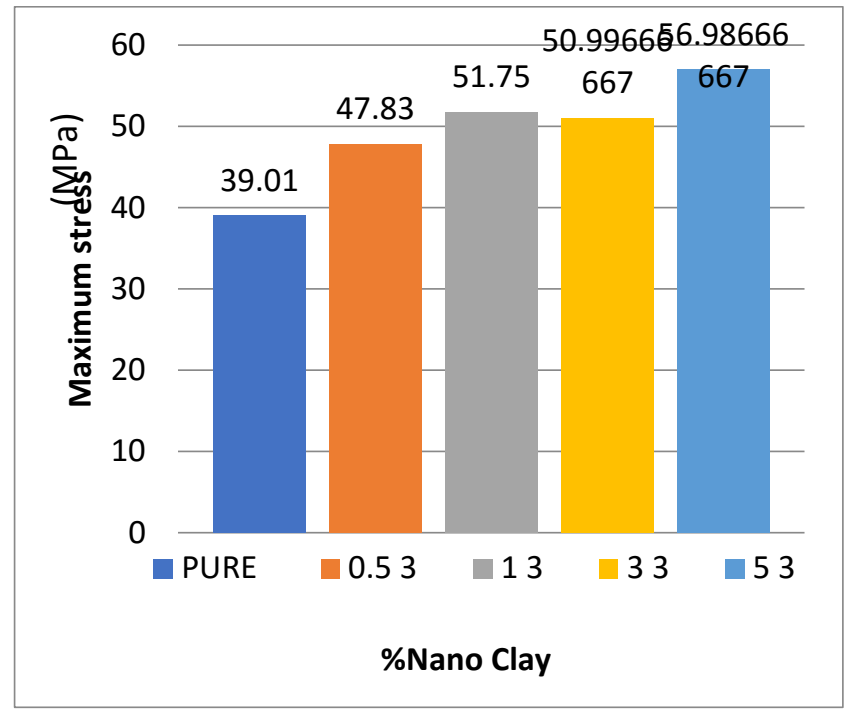

Fig Graph between \%NANO VS Flexure load at Maximum Flexure stress

The between \%of Nano clay and flexure load at maximum flexure stress on $\mathrm{x}, \mathrm{y}$-axis observes that as the increasing of Nano clay addition of weight percentage increases flexureload also increases gradually. As the clay content increases from $1 \mathrm{Wt} \%$ to $5 \mathrm{Wt} \%$ flexural modulus tends to increase and compared to other percentages of Nano clay and other materials like HDPE and ABS.

\section{FESEM Images of Nanocomposites}

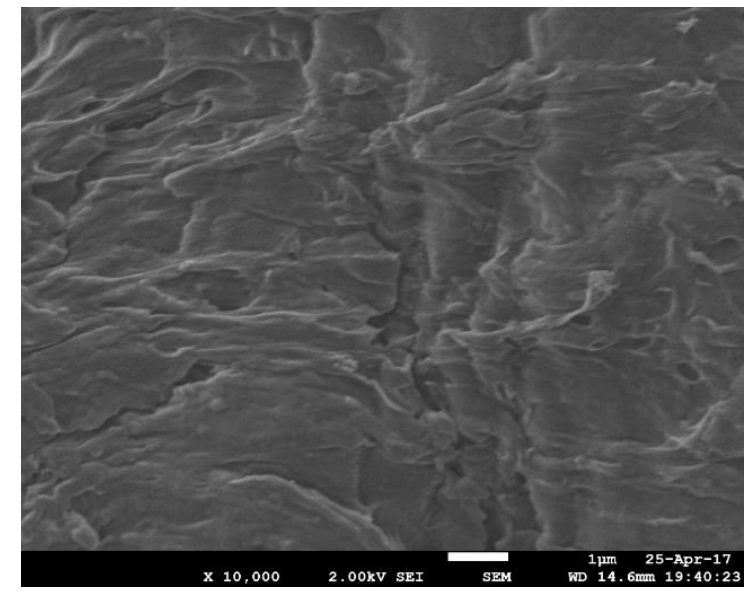

Fig. 17 FESEM image of $3 \%$ Nano clay treated with ABS material

From the above image Fig. 17 it is observed that the reinforcement of Nano clay $3 \mathrm{Wt} \%$ in ABS material are clearly visible within the plastic matrix. But the ABS Nanocomposite material immersed 
in distilled water upon exposed to larger time water absorption severely damaged the matrix interface. This causes a poor adhesion between the plastic matrixes. Due to poorer adhesion of ABS Nanocomposite material tends to decrease the mechanical properties of ABS nanocomposite.

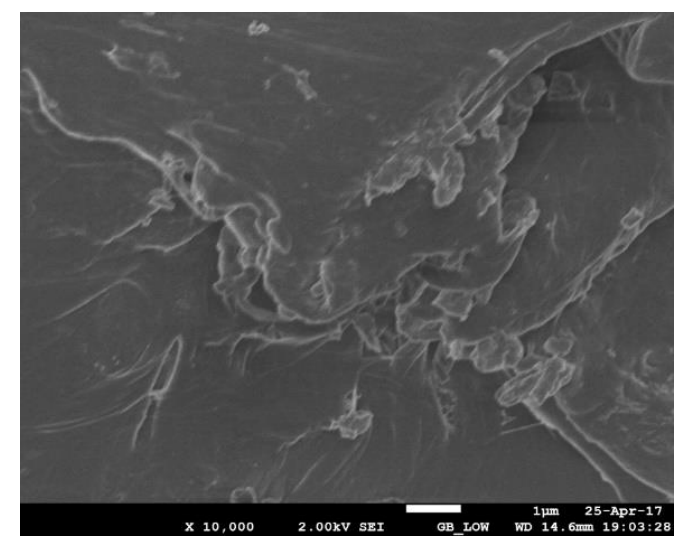

Fig.18 FESEM image of 3\% Nano clay treated with HDPE material

From the above image Fig. 18 it is observed that the reinforcement of Nano clay $3 \mathrm{Wt} \%$ in HDPE material are clearly visible within the plastic matrix. But the HDPE Nanocomposite material immersed in distilled water upon exposed to larger time water absorption severely damaged the matrix interface. This causes a poor adhesion between the plastic matrixes. Due to poorer adhesion of HDPE Nanocomposite material tends to decrease the mechanical properties of HDPE nanocomposite.

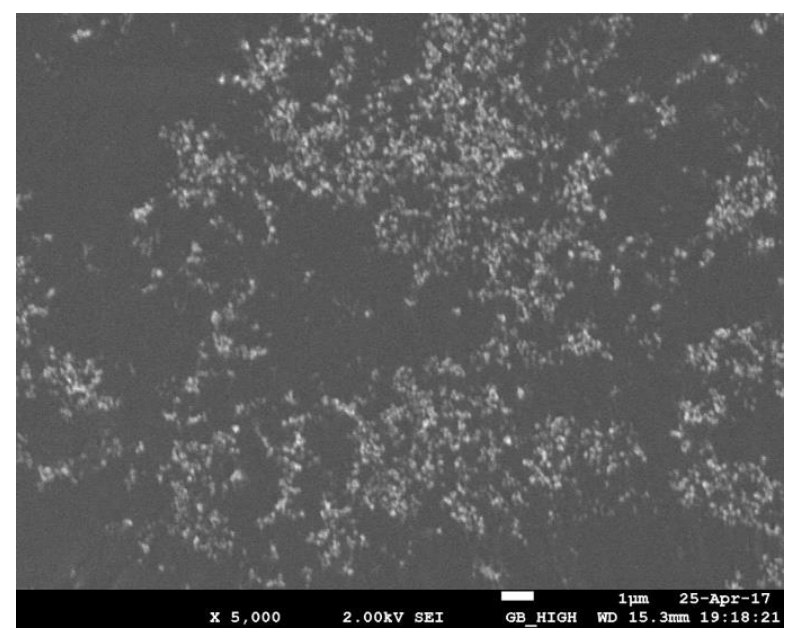

Fig.19 FESEM image of 3\% Nano clay treated with PP material

From the above image Fig.19 it is observed that the reinforcement of Nano clay 3Wt\% in PP material are clearly visible within the plastic matrix. But the PP Nanocomposite material immersed in distilled water upon exposed to larger time water absorption severely damaged the matrix interface. This causes a poor adhesion between the plastic matrixes. Due to poorer adhesion of PP Nanocomposite material tends to decrease the mechanical properties of PP nanocomposite.

\section{CONCLUSIONS AND FUTURE SCOPE}

The present study concerning its effect on the mechanical properties of the clay-reinforced $\mathrm{PP}, \mathrm{ABS}$ and HDPE has led to the following conclusions . 
The Mechanical properties of the as-moulded materials, i.e. the elastic modulus and the maximum stress, increase upon introduction of the Nano clay particles into the PP, ABS and HDPE. This is attributed not only to the conventional reinforcing effect of the high-modulus clay, but also to the fact that the many Nano scale particles present restrict the mobility of the matrix polymer chains in the interfacial region, thus contributing further to the improvement in mechanical properties of the polymer clay hybrid composites.

The presence of the Nano clay particles in the PP, ABS and HDPE matrix promotes and used in this study. The clay particles can also promote the creation of micro pores in the PP, ABS and HDPE matrix, accelerating therefore the diffusion the molecules in the nanocomposite materials. For a given material, the temperature dependence of the melting point of its individual.

Finally, the experiments and tests done on different percentages of Nano clay examined that increase in strength due to nanoclay addition. Actually in process there will be less decrease of strength and youngsmodulus in ABS when compared to polypropylene and high density polyethylene. So ABS is better because the reduction strength is less when compared to polypropylene and high density polyethylene.

The use of a nanocomposite materials for packaging film and automotive panels, however, has no obvious environmental benefit. From an economic point of view, the use of a nanocomposite in packaging film is advantageous if the Nano clay price is not higher Depending on which material and energy prices are assumed, the life cycle costs can be reduced by 26-39\% when a nanocomposite material is used for agricultural film. We estimated the economic advantage of using Nano composites in automotive applications to be 3-6\%.

Based on the results of this study, we can conclude that the use of nanocomposite material can have clear advantages over conventional material in certain circumstances. These advantages are mainly caused by a reduction in the amount of material needed, which depends on material properties like the Young modulus and tensile strength. We found, for example, a high increase in these properties compared to those which have less properties of materials, which explains the large reduction in material.

Moreover, they show some economic benefits when used in agricultural film and automotive panels and definite environmental benefits in the case of agricultural film. One exception to the use of Nano composites may be the toxic effects of free nanoparticles: more research is required on this topic. Provided the potential release of free nanoparticles from polymer Nano composites can be excluded as source of concern for human health and the environment, the outcomes of the required Nano clay price reduction to make nanocomposite cases clearly support further polymer research and technology development.

- Increasing the nanoclay content from 0 to $5 \mathrm{wt} \%$ increases the Mechanical Properties of the three samples HDPE, PP and ABS.

- Among these materials ABS performing better tensile strength at $5 \%$ of nanoclay addition with $30.95 \%$ of increasing its strength when comparing to the pure values and young's modulus also increasing with $35 \%$.

- By increasing the nanoclay weight percentage the flexural stress and modulus also increasing gradually to these three samples ABS,PP and HDPE.

- Among these materials ABS showing better flexural strength at $5 \%$ of nanoclay addition with $39.3 \%$ of increasing its strength when comparing to the pure values and modulus also increasing with $68 \%$ respectively when comparing these values with PP and HDPE also

\section{- PERCENTAGE OF INCREMENT IN TENSILE STRENGTH:}

\begin{tabular}{|c|c|c|c|c|}
\hline $\begin{array}{c}\text { TENSILE } \\
\text { STRENGTH }\end{array}$ & $0.5 \%$ & $1 \%$ & $3 \%$ & $5 \%$ \\
\hline ABS & 14.07 & 18.09 & 22.58 & 30.95 \\
\hline HDPE & 2.5 & 9.599 & 10.89 & 13.7 \\
\hline
\end{tabular}




\begin{tabular}{|l|l|l|l|l|}
\hline PP & 4.97 & 5.85 & 10.48 & 11.09 \\
\hline
\end{tabular}

- PERCENTAGE OF INCREMENT IN E :

\begin{tabular}{|c|c|c|c|c|}
\hline E & $\mathbf{0 . 5 \%}$ & $\mathbf{1 \%}$ & $\mathbf{3 \%}$ & $\mathbf{5 \%}$ \\
\hline ABS & $\mathbf{1 6 . 2 4}$ & $\mathbf{1 6 . 5 6}$ & $\mathbf{1 8 . 4 3}$ & $\mathbf{3 5}$ \\
\hline HDPE & $\mathbf{1 9 . 8 1}$ & $\mathbf{3 1 . 1 3}$ & $\mathbf{3 0 . 1 3}$ & $\mathbf{3 2 . 4}$ \\
\hline PP & $\mathbf{1 . 4 2}$ & $\mathbf{2 . 4 2}$ & $\mathbf{4 . 3 6}$ & $\mathbf{7 . 7 6}$ \\
\hline
\end{tabular}

- PERCENTAGE OF INCREMENT IN FLEXURAL STRENGTH:

\begin{tabular}{|l|c|c|c|c|}
\hline Flexural stress & $\mathbf{0 . 5 \%}$ & $\mathbf{1 1 \%}$ & $\mathbf{3 \%}$ & $\mathbf{5 \%}$ \\
\hline ABS & $\mathbf{1 1 . 0 9}$ & $\mathbf{2 6 . 5 8}$ & $\mathbf{3 7 . 9 7}$ & $\mathbf{3 9 . 3}$ \\
\hline HDPE & $\mathbf{3 . 4 5}$ & $\mathbf{5 . 6 6}$ & $\mathbf{7 . 8 9}$ & $\mathbf{1 2 . 4 9}$ \\
\hline PP & 1.2 & 1.6 & $\mathbf{2 . 0 6}$ & $\mathbf{3 . 4 5}$ \\
\hline
\end{tabular}

- PERCENTAGE OF INCRIMENT IN E:

\begin{tabular}{|l|c|c|c|c|}
\hline E & $0.5 \%$ & $11 \%$ & $3 \%$ & $5 \%$ \\
\hline ABS & 3.06 & 51.03 & 57.15 & 68.52 \\
\hline HDPE & 1.2 & 2.45 & 11.3 & 17.78 \\
\hline PP & 1.18 & 8.4 & 9.85 & 22.1 \\
\hline
\end{tabular}

\section{References}

1. RahelehHeidarPour, Mohammad Soheilmoghaddam, Azman Hassan Serge Bourbigot "Flammability and thermal properties of polycarbonate /acrylonitrilebutadiene-styrene nanocomposites reinforced with multilayer grapheme",Polymer Degradation and Stability , 120 (2015) 88e97. 
2. Priyanka Singh, Anup K. Ghosh "Torsional, tensile and structural properties of acrylonitrilebutadiene-styrene clay nanocomposites", Materials and Design 55 (2014) 137-145.

3. ZhafiUllahKhan ,ArshadMunir, RizwanHussain, Jang-Kyo Kim "Fatigue damage behaviour of carbon fiber-reinforced epoxy composites containing nanoclay", Composites Science and Technology 70 (2010) 2077-2085.

4. C.M. Manjunatha, Ramesh Bojja , N. Jagannathan, A.J. Kinloch, A.C. Taylor "Enhanced fatigue behavior of a glass fiber reinforced hybrid particles modified epoxy nanocomposite under WISPERX spectrum load sequence", International Journal of Fatigue 54 (2013) 25-31.

5. Muhammad A.S. Anwer, Hani E. Naguib"Study on the morphological, dynamic mechanical and thermal properties of PLA carbon nanofibre composites", Composites Part B 91 (2016) $631 \mathrm{e} 639$.

6. K. Kanny P. Jawahar V. K. Moodley, "Mechanical and tribologicalbehavior of claypolypropylene Nanocomposites", Sci (2008) 43:7230-7238.

7. SajjadMamaghaniShishavan, TaherAzdast, Samrand Rash Ahmadi, "Investigation of the effect of nanoclay and processing parameterson the tensile strength and hardness of injection moldedAcrylonitrile Butadiene Styrene-organoclaynanocomposites", Materials and Design58 (2014) 527-534.

8. Mohammed H. Al-Saleh, Bader A. Al-Saidi, Raed M. Al-Zoubi "Experimental and theoretical analysis of the mechanical and thermal properties of carbon nanotube/acrylonitrilestyrenebutadienenanocomposites", Polymer 89 (2016) 12e17.

9. Shaofeng Wang, Yuan Hu , Lei Song, Zhengzhou Wang, Zuyao Chen , WeichengFan, "Preparation and thermal properties of ABS/montmorilloniteNanocomposite",Polymer Degradation and Stability 77 (2002) 423-42.

10. M. Modesti, S. Besco, A. Lorenzetti, V. Causin, C. Marega, J.W. Gilman,D.M. Fox, .C. Trulove, H.C. De Long, M. Zammarano, "ABS/clay nanocomposites obtained by a solution technique:Influence of clay organic modifiers", Polymer Degradation and Stability 92 (2007) $2206 \mathrm{e} 2213$.

11. K. Kanny, V. K. Moodley, "Characterization of polypropylene Nanocomposite structures", Materials technology, volume 129, January 2007 pages 106-112.

12. S. Al-Malaika, H. Sheena, D. Fischer, E. Masarati, "Influence of processing and clay type on nanostructure and stability of polypropyleneclay nanocomposites" ,Polymer Degradation and Stability, volume 98 (2013) pages 2400-2410.

13. David Arencon and Jose Ignacio Velasco, "Fracture Toughness of Polypropylene-Based ParticulateComposites", Materials, volume 2, (2002)pages 2046-2094.

14. Mohammad-Javad Khalaj, Hamidreza Ahmadi, Rasoul Lesankhosh,Gholamreza Khalaj, "Study of physical and mechanical properties of polypropylene nanocomposites for food packaging application: Nano-clay modified with iron nanoparticles",Trends in food science and technology, Elsveir, volume 512016 pages 41-48.

15. Achmad Chafidz, Mohammad Al-haj Ali, Rabeh Elleithy, "Morphological, thermal, rheological, and mechanical properties of polypropylene-Nano clay composites prepared from masterbatch in a twin screw extruder" Journal of material science, volume 46 (2011) pages 6075-6086.

16. Ivan Kelnar, Jiri Hodan, Ludmila Kapr_alkov, Jaroslav Kratochvil, Jirina Hromadkov, Jiri Kotek, "J-integral evaluation of nanoclay-modified HDPE/PA6 microfibrillar composites", Polymer testing, volume 58 (2017) pages 54-59.

17. Burak Kutlu, Juliane Meinl, Andreas Leuteritz, Harald Brünig, Gert Heinrich, "Melt-spinning of LDH/HDPE nanocomposites", Polymer, (2013) volume 54 pages 5712-5718.

18. David Chu, Quang Nguyen, Donald G.Baird, "Effect of matrix molecular weight on the dispersion of nanoclay in unmodified high density polyethylene", Polymer composites, volume 28 issue 4, August 2007 pages 499-511.

19. Atul Rajan1, Pradeep Upadhya andNavin Chandet "Morphological, thermal, rheological, and mechanical properties of polypropylene-Nano clay composites prepared from masterbatch in a twin screw extruder" Journal of material science, volume 46 (2011) pages 6075-6086. 
20. Akram Tavakoli, Mir Karim Razavi Aghjeh, Mohammad Rahi, "Effect of nanoclay on the morphology of polyethylene modified bitumen", Construction and building materials, volume 116 (2016) pages 245-251.

21. Biplab K. Deka, T.K. Maji,"Effect of coupling agent and nanoclay on properties of HDPE, LDPE, PP, PVC blend and Phargamites karka nanocomposite",Composite science and technology, volume 70 (2010) pages 1755-1761.

22. Othman Y Alothman H Fouad S M AlZahrani Ayman Eshra Mohammed Fayez Al Rez S G Ansari, "Thermal, creep-recovery and viscoelastic behavior of high density polyethylene/hydroxyapatite nano particles for bone substitutes: effects of gamma radiation", springer, December 2014, volume 13 page 125. 